\title{
Pengembangan Aplikasi Partisipatif Ruang Terbuka Hijau Wilayah Provinsi Jawa Barat
}

\author{
Sumarno dan Indrianawati \\ Jurusan Teknik Geodesi, FTSP - Institut Teknologi Nasional, Bandung \\ Email: indrianawati86@gmail.com
}

\begin{abstract}
ABSTRAK
Proporsi Ruang Terbuka Hijau (RTH) pada suatu wilayah ditargetkan minimal 30\% dari luas wilayah kota. Kenyataannya pemerintah kabupaten/kota di Provinsi Jawa Barat belum ada yang dapat memenuhi target tersebut. Dalam rangka memfasilitasi pemerintah kabupaten/kota untuk memenuhi target RTH, Dinas Permukiman dan Perumahan Provinsi Jawa Barat telah membangun sistem informasi RTH. Penelitian ini bertujuan untuk mengembangkan sistem informasi RTH yang telah dibangun dengan menyusun database RTH kabupaten/kota di Jawa Barat dalam aplikasi berbasis webGIS dan tersedia informasi mengenai Rencana Detail Tata Ruang kabupaten/kota di Jawa Barat yang dapat menjadi instrumen inventarisasi dan pengelolaan data mengenai RTH di Jawa Barat. Metode yang digunakan untuk mengembangkan aplikasi yang telah terbangun adalah fusebox. Hasil yang diperoleh adalah berupa aplikasi partisipatif berbasis webGIS yang dapat diakses oleh publik secara online.
\end{abstract}

Kata kunci: Ruang Terbuka Hijau, aplikasi partisipatif, webSIG

\begin{abstract}
Proportion of Green Open Space in a region is targeted at least 30\% of city area. The regency/city government in West Java Province has not been able to meet that target. In order to facilitate regency/city governments to meet the target of green open space, Department of Housing and Settlement in Province West Java has built an information system on green open space. This research aims to develop information system of green open space that has been built by arranging green open space database of regency/city in West Java in webGIS based application and provide information about Spatial Plan Details of regency/city in West Java which can be instrument to inventory and management of data about green open space in West Java. The method used to develop applications that have been built is fusebox. The results obtained are a web-based participatory application that can be accessed by the public online.
\end{abstract}

Keywords: Green Open Space, participatory application, webGIS 


\section{PENDAHULUAN}

Ruang Terbuka Hijau (RTH) adalah area memanjang/jalur dan atau mengelompok, yang penggunaannya lebih bersifat terbuka, tempat tumbuh tanaman, baik yang tumbuh tanaman secara alamiah maupun yang sengaja ditanam [1]. Ruang Terbuka Hijau merupakan salah satu komponen penting dalam perencanaan ruang kawasan pada saat ini. Secara kuantitas dan kualitas RTH mengalami penurunan yang sangat signifikan dan mengakibatkan penurunan kualitas lingkungan hidup perkotaan sehingga berdampak terhadap terjadinya banjir dan peningkatan pencemaran udara. Dalam [2] Pasal 29, telah diamanatkan bahwa RTH ditargetkan minimal 30\% dari luas wilayah kota, meliputi 20 (dua puluh) persen RTH publik dan sisanya merupakan RTH privat. Proporsi $30 \%$ ini merupakan ukuran minimal untuk menjamin keseimbangan ekosistem kota, baik keseimbangan sistem hidrologi dan keseimbangan mikroklimat, maupun sistem ekologis lain yang dapat meningkatkan ketersediaan udara bersih yang diperlukan masyarakat, serta sekaligus dapat meningkatkan nilai estetika kota.

Terkait dengan RTH, Gubernur selaku pemerintah provinsi juga bertanggung jawab dalam penyelenggaraan SPM (Standar Pelayanan Minimal) Bidang Pekerjaan Umum dan Penataan Ruang sebagaimana yang telah diamanatkan dalam [3], dimana salah satu indikatornya adalah ketersediaan RTH publik sebesar $20 \%$ dari luas wilayah kota/kawasan perkotaan. Secara realita, pemerintah kabupaten/kota di Jawa Barat belum ada yang dapat memenuhi target tersebut. Dalam [4] dijelaskan bahwa permasalahan Ruang Terbuka Hijau di kota/kabupaten yang berada di Jawa Barat, terdiri dari: perkembangan kota yang pesat, sehingga banyak terjadi peralihan fungsi lahan dari kawasan budidaya pertanian menjadi kawasan permukiman; sebagian besar RTH privat pada pertanian perkotaan sudah beralih fungsi menjadi lahan terbangun (komersil); sempadan sungai yang ada di wilayah perencanaan hampir sebagian besar menjadi daerah terbangun; kesadaran masyarakat sebagai bagian dari stakeholder kurang paham dan peduli akan pentingnya RTH, walaupun ada kebanyakan belum bisa menjaga dan memelihara RTH yang ada, seperti taman lingkungan perumahan; RTH di bawah Jaringan SUTT dan SUTET belum sepenuhnya dapat dibebaskan, sehingga masih banyak dipergunakan fungsinya untuk selain RTH; penanganan RTH yang belum dilakukan secara maksimal dengan melibatkan swasta dan masyarakat; keberadaan lapangan parkir terbuka tidak dibarengi dengan penghijauan/penanaman pohon pelindung, sehingga termasuk kriteria ruang terbuka saja; keberadaan pelaku ekonomi/PKL di sekitar kawasan taman kota menyebabkan terganggunya tanaman atau vegetasi yang ada; RTH privat, khususnya untuk pekarangan perumahan masih kurang, hal ini terlihat dari banyaknya rumah yang menghabiskan seluruh luas kavling lahannya untuk dibangun rumah sehingga tidak memiliki pekarangan; belum ada tindakan yang tegas dari pihak berwenang/terkait bagi pelanggar atau perusak RTH yang ada; serta kurangnya sosialisasi mengenai RTH oleh instansi terkait kepada masyarakat, sehingga menyebabkan masih banyak RTH privat yang tidak sesuai dengan ketentuan yang berlaku.

Data mengenai RTH eksisting dan RTH potensial beserta pengelolaannya di kabupaten/kota se-Jawa Barat merupakan data yang sangat krusial bagi Pemerintah Provinsi Jawa Barat untuk mengetahui kondisi RTH kabupaten/kota di Jawa Barat karena data tersebut digunakan sebagai dasar dalam penyusunan dan pengambilan kebijakan dalam rangka pemenuhan target RTH. Pemerintah Provinsi Jawa Barat diharapkan dapat meningkatkan peran fasilitasi terhadap kabupaten/kota dalam mewujudkan amanat tersebut, sehingga Pemerintah Provinsi Jawa Barat melalui Dinas Permukiman dan Perumahan Jawa Barat telah membangun sebuah sistem informasi RTH.

Dalam penelitian ini dilakukan penyempurnaan dalam pengembangan sistem informasi Ruang Terbuka Hijau yang telah dibangun, dalam bentuk pengisian database mengenai Ruang Terbuka Hijau, serta membangun sistem informasi tentang Rencana Detail Tata Ruang (RDTR) kabupaten/kota di Jawa Barat sebagai dokumen rinci yang merupakan database RTH. Tujuan dari penelitian ini adalah mengembangkan aplikasi partisipatif RTH dengan tersusunnya database RTH kabupaten/kota di Jawa Barat dalam aplikasi berbasis webGIS dan tersedianya informasi mengenai RDTR kabupaten/kota di Jawa Barat yang dapat menjadi instrumen inventarisasi dan pengelolaan data serta sarana informasi publik mengenai RTH di Jawa Barat. Pengembangan aplikasi partisipatif ini 
diharapkan dapat mendorong pencapaian target pemenuhan RTH kabupaten/kota se-Jawa Barat dengan mengintegrasikan data aspek perencanaan hingga pengawasan dan pengendalian RTH.

\section{METODOLOGI}

Metodologi yang digunakan dalam penelitian ini adalah fusebox, yaitu suatu pengembangan aplikasi berbasis web dengan menyederhanakan aplikasi web menjadi beberapa bagian [5]. Konsep fusebox adalah memecah aplikasi menjadi bagian-bagian kecil sehingga aplikasi yang dikembangkan menjadi lebih mudah untuk dikelola. Proses untuk mengembangkan aplikasi web yang dilakukan adalah menggunakan FLiP (Fusebox Lifecycle Process). FLiP terdiri dari beberapa tahapan, yaitu [6]:

1) Identifikasi kebutuhan pengguna

2) Wireframing (pembuatan kerangka sederhana dari aplikasi)

3) Prototype/Front-End Development (aplikasi sementara berupa html yang dapat diklik)

4) Arsitektur aplikasi (menurunkan aplikasi ke dalam circuit, fuseaction, dan fuses)

5) Fusecoding (membuat kode)

6) Unit testing (menguji sistem aplikasi)

\subsection{Hasil Analisis dan Perancangan}

\section{HASIL DAN PEMBAHASAN}

Analisis dan perancangan sistem dilakukan berdasarkan data yang diperoleh dan disesuaikan dengan kebutuhan. Hasil analisis dan perancangan sistem dituangkan menjadi sebuah prototype dan struktur website yang selanjutnya dipresentasikan menjadi sebuah sistem aplikasi. Struktur website RTH dapat dilihat pada Gambar 1.

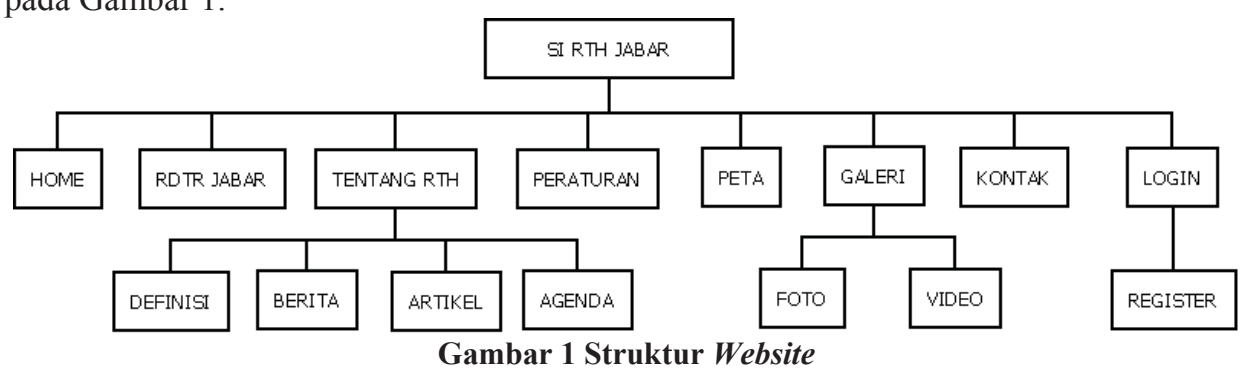

Database yang dibuat untuk pengembangan sistem informasi RTH menggunakan program database MySQL. Pembuatan database disesuaikan dengan kebutuhan pengguna (user) dan data RTH yang tersedia. Pembuatan database RTH dapat dilihat pada Gambar 2.

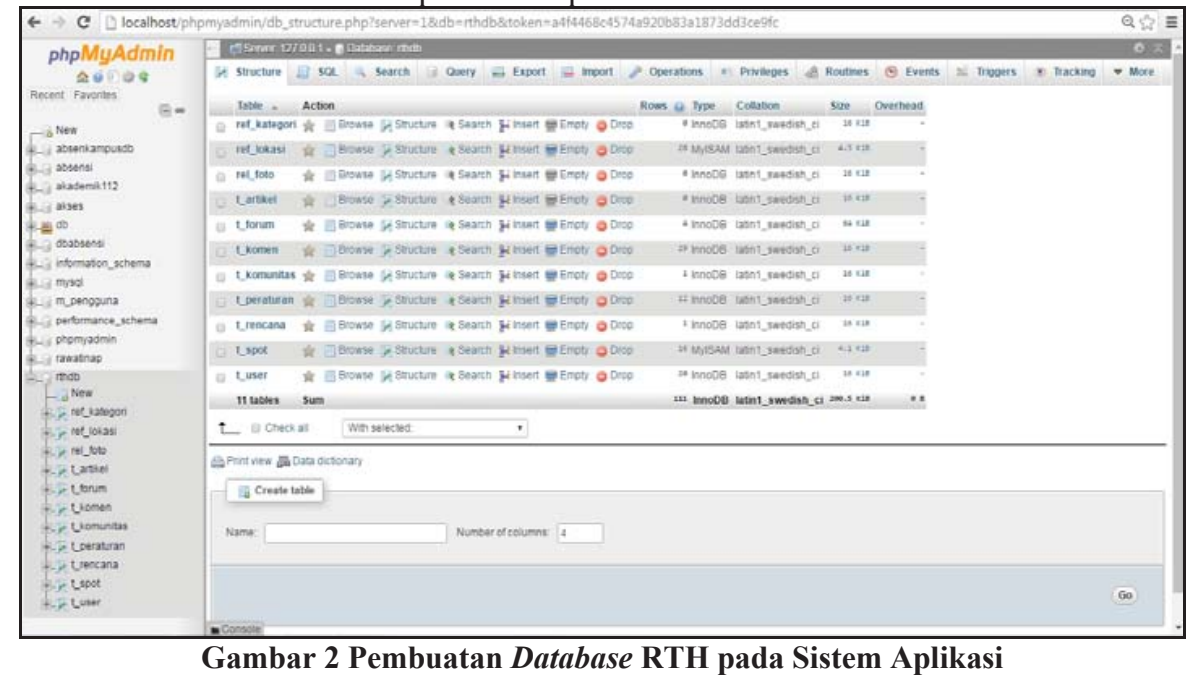




\subsection{Hasil Pengembangan Aplikasi}

Pengembangan aplikasi partisipatif Ruang Terbuka Hijau menghasilkan sebuah aplikasi sesuai dengan perancangan dan desain yang telah dilakukan. Hasil pengembangan aplikasi Ruang Terbuka Hijau merupakan sebuah webGIS yang di dalamnya memberikan informasi data sebaran lokasi RTH kabupaten/kota di Jawa Barat. Aplikasi RTH yang dibangun terdiri dari:

a. menu utama (home), yaitu halaman utama aplikasi yang memberikan informasi awal tentang $\mathrm{RTH}$

b. menu tentang RTH, yaitu halaman yang memberikan informasi tentang pengertian RTH, istilah-istilah RTH, dan tujuan RTH;

c. menu peraturan, yaitu halaman yang memberian informasi tentang peraturan-peraturan pemerintah mengenai RTH;

d. menu galeri, yaitu halaman yang memberikan informasi tentang dokumentasi mengenai RTH dan kegiatan di lingkungan RTH;

e. menu peta, yaitu halaman yang memberikan informasi peta sebaran lokasi RTH di seluruh kabupaten/kota di Jawa Barat (informasi ini merupakan informasi yang paling penting pada aplikasi sistem informasi ini dibuat);

f. menu diskusi, yaitu halaman yang memberikan informasi tentang diskusi-diskusi antara pengguna (user) aplikasi dan pihak pengelola aplikasi;

g. menu kontak, yaitu halaman yang memberikan informasi alamat pengelola (admin); dan

h. menu login, yaitu halaman yang memberikan informasi untuk mendaftar sebagai pengguna (user) aplikasi.

Berikut visualisasi aplikasi RTH yang telah dibangun dapat dilihat pada Gambar 3 s.d. Gambar 10.

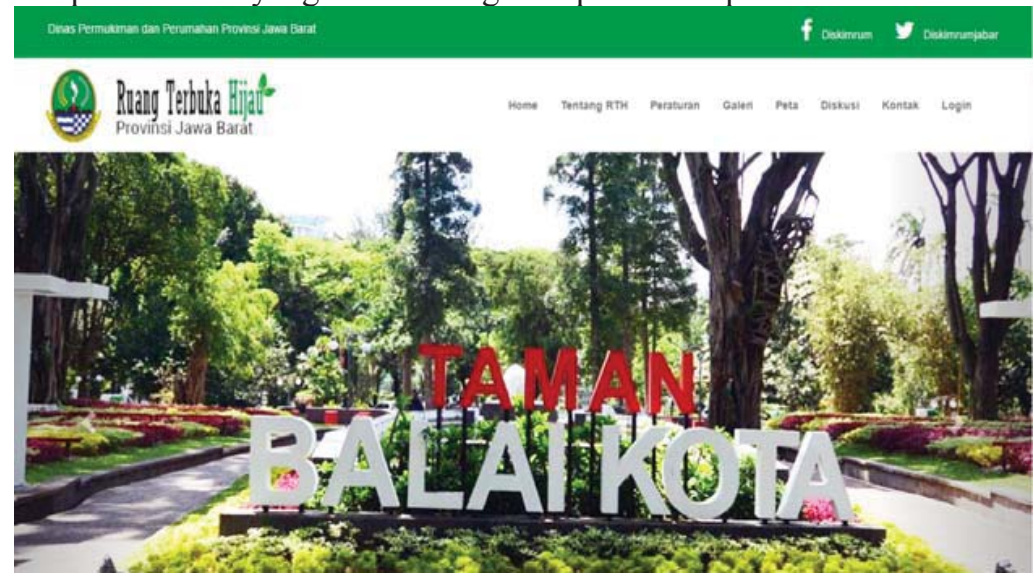

Gambar 3 Menu Utama

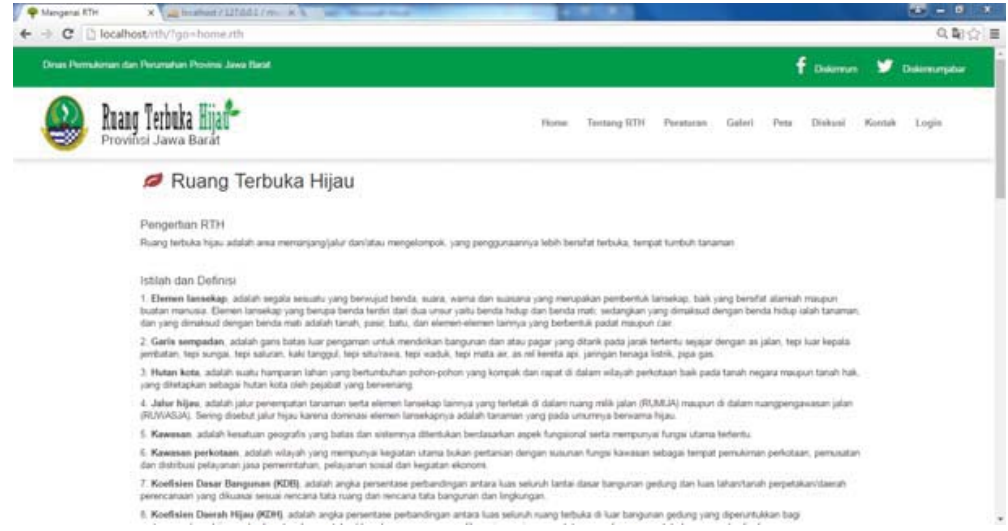

Gambar 4 Menu Tentang RTH

Jurnal Rekayasa Hijau - 34 


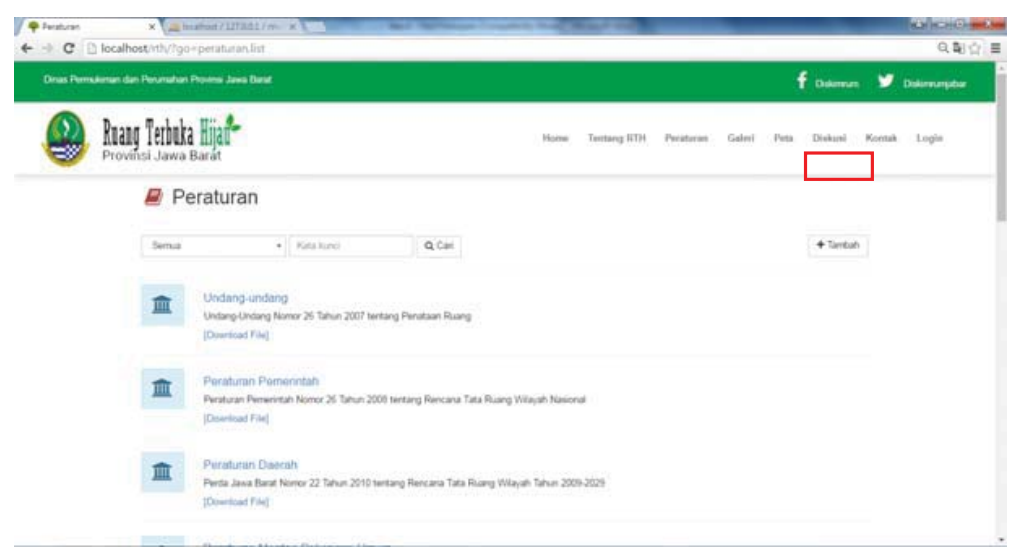

Gambar 5 Menu Peraturan

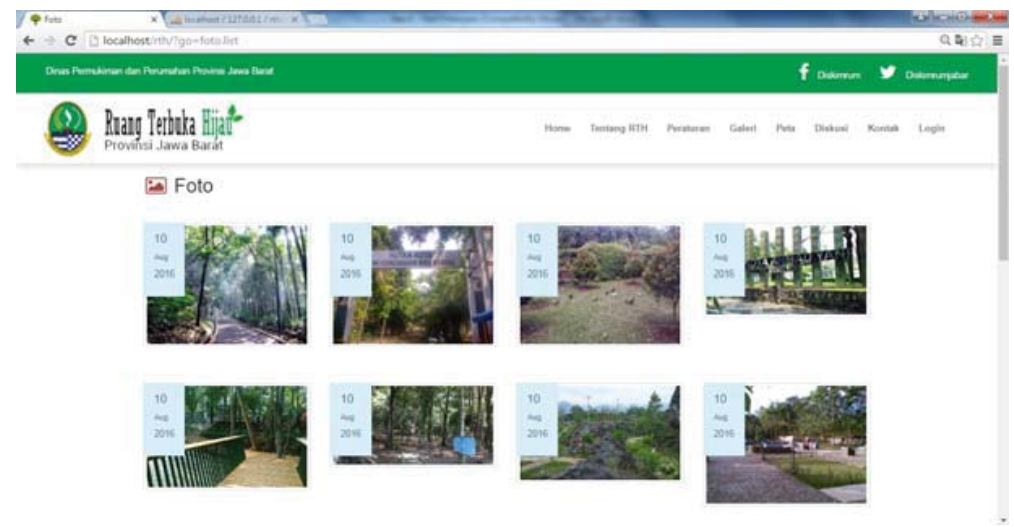

Gambar 6 Menu Galeri

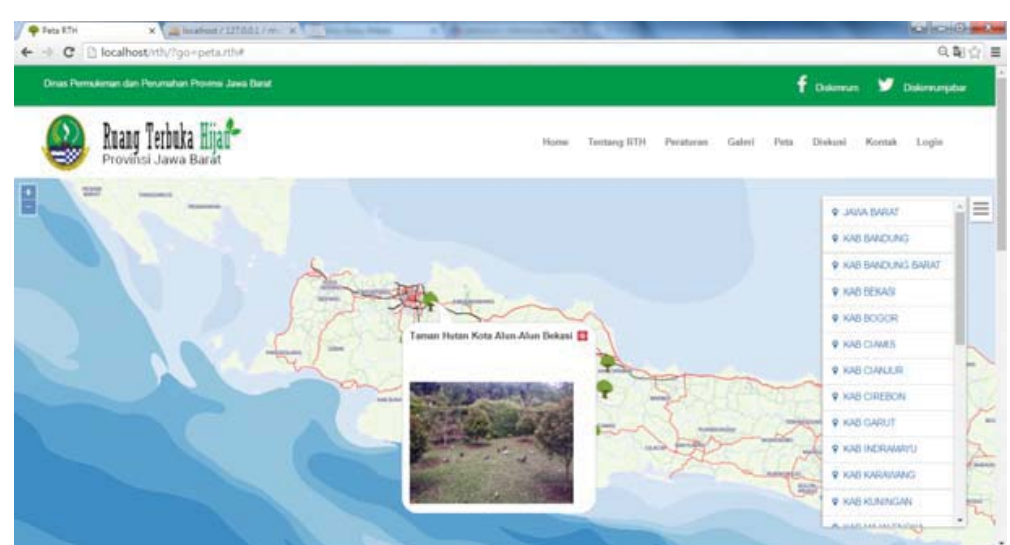

Gambar 7 Menu Peta 
Sumarno dan Indrianawati

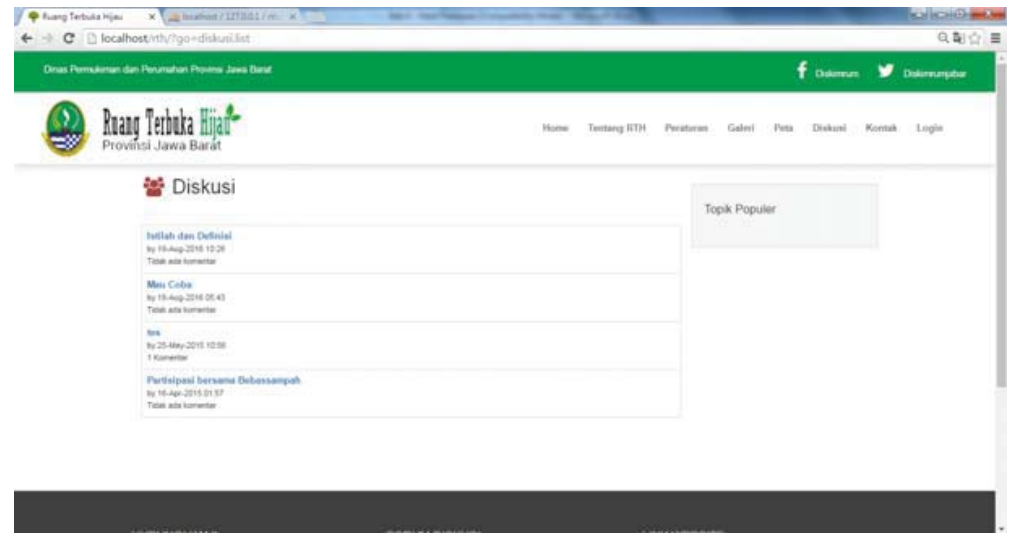

Gambar 8 Menu Diskusi

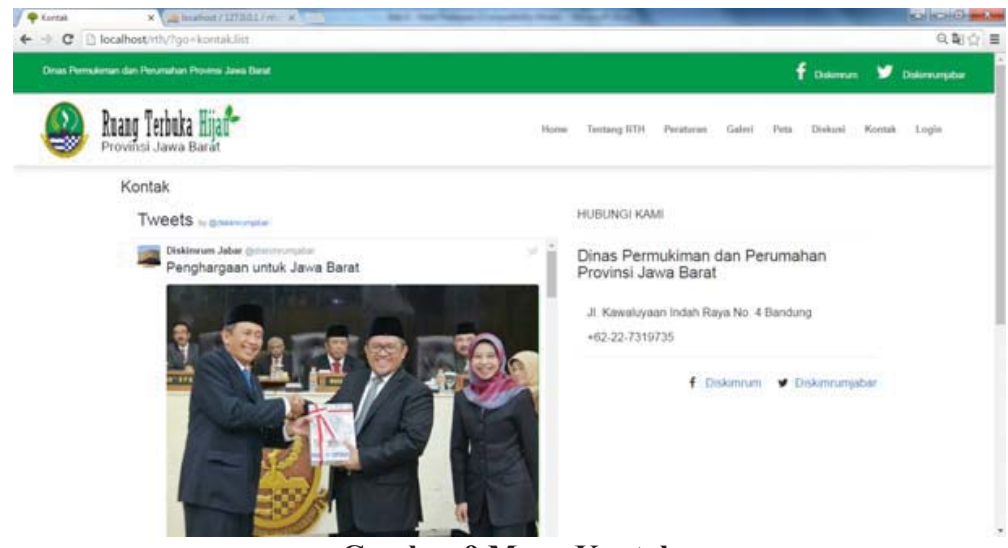

Gambar 9 Menu Kontak

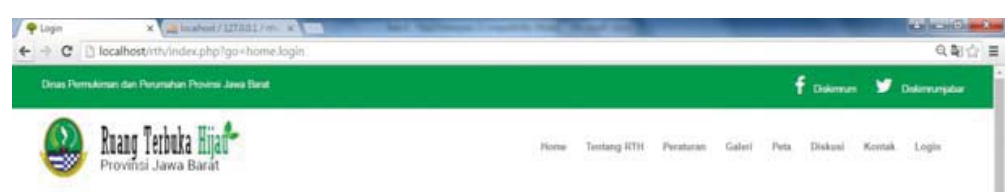

Apa itu Sistem Informasi RTH?
Media untuk memfasilitasi komunikasi dan informasi antar

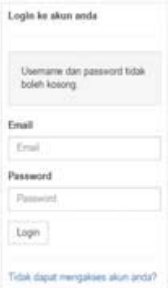

Gambar 10 Menu Login

\subsection{Hasil Perubahan Aplikasi}

Aplikasi partisipatif yang telah dikembangkan terdapat perubahan atau perbaikan berdasarkan masukan dari Dinas Permukiman dan Perumahan Provinsi Jawa Barat. Perubahan tersebut adalah penambahan kolom berita, artikel, dan agenda pada menu utama; serta penambahan menu RDTR dan menu link pada aplikasi. Menu RDTR yaitu halaman yang berisi peraturan daerah mengenai RDTR seluruh kabupaten/kota di Provinsi Jawa Barat. Menu link yaitu halaman yang berisi website 
Pemetaan Potensi Sumber Daya Perkebunan Untuk Komoditas Strategis di Provinsi Jawa Barat

pemerintah, komunitas, dan lain-lain yang berkaitan dengan RTH. Perubahan aplikasi tersebut dapat dilihat pada Gambar 11 s.d. Gambar 13.
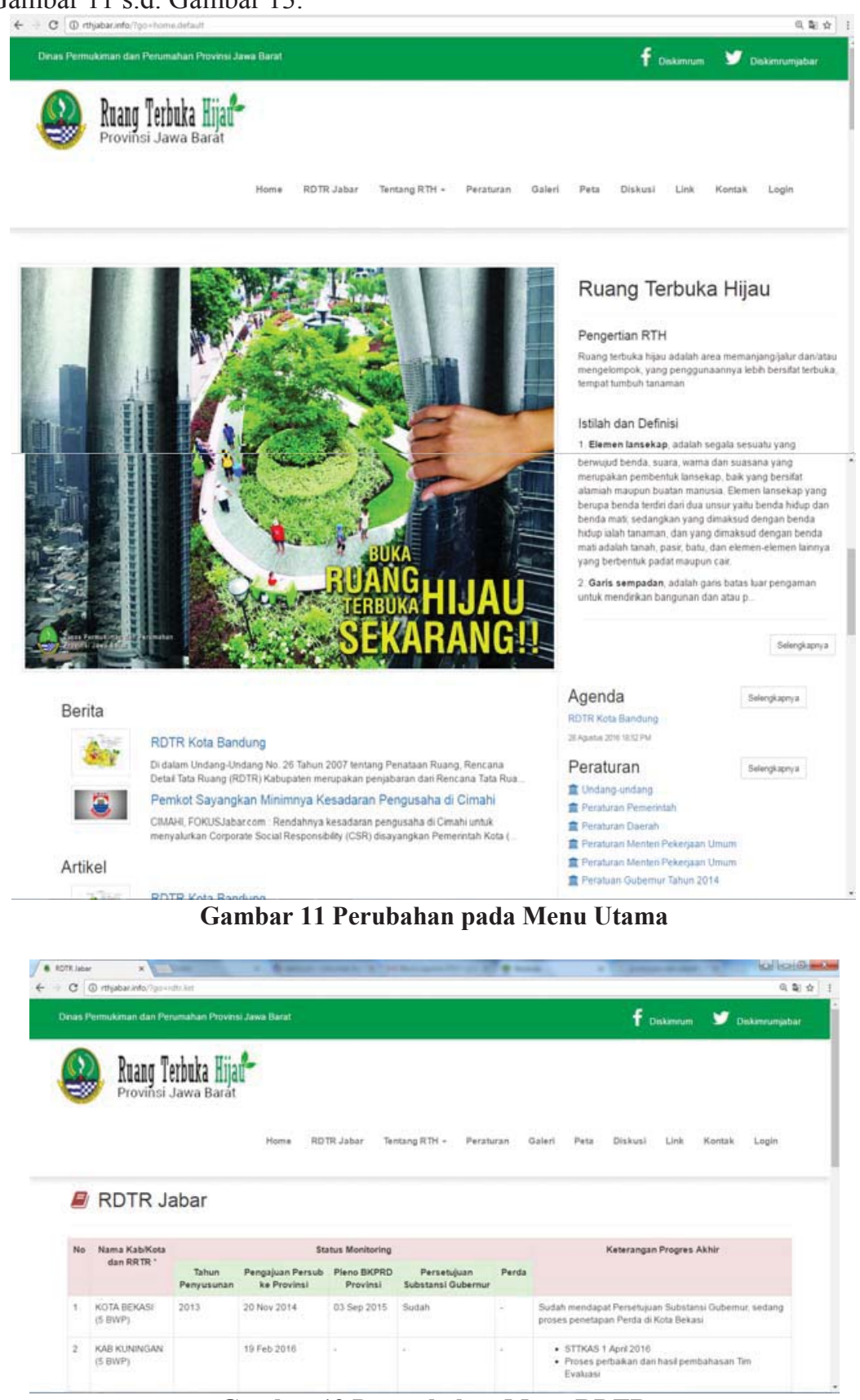

Gambar 12 Penambahan Menu RDTR 


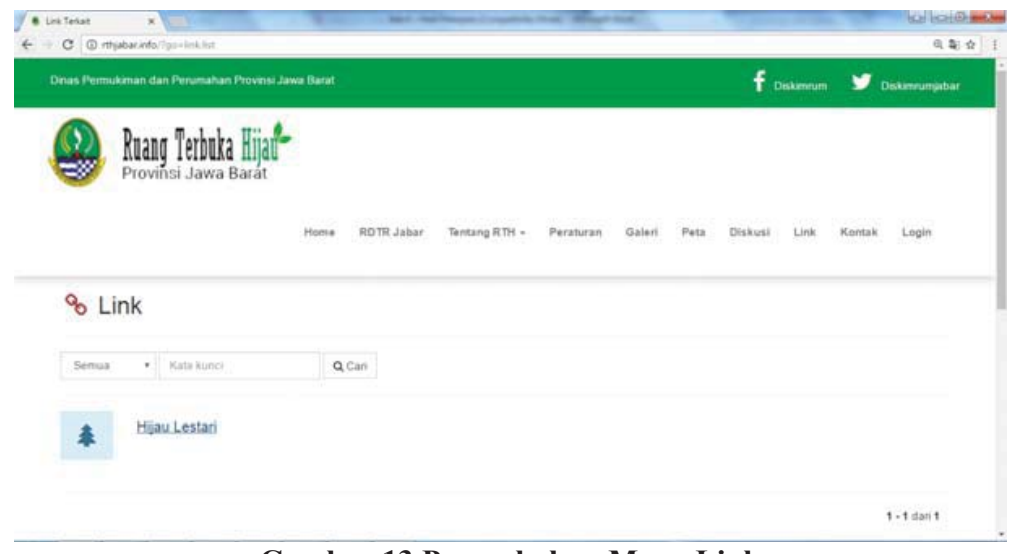

Gambar 13 Penambahan Menu Link

\subsection{Uji Coba Sistem (Testing) dan Implementasi Sistem Aplikasi}

Setelah dilakukan pengembangan aplikasi, selanjutnya dilakukan uji coba. Hasil pengujian aplikasi yang dibangun adalah aplikasi dapat berfungsi dengan baik dan dapat diimplementasikan dengan baik. Implementasi sistem aplikasi terdiri dari langkah-langkah sebagai berikut:

a. Menerapkan rencana implementasi

Rencana implementasi dimaksudkan terutama untuk mengatur waktu yang diperlukan untuk melakukan kegiatan dalam rencana implementasi dalam bentuk jadwal waktu. Jadwal waktu berfungsi sebagai pengendalian terhadap waktu implementasi.

b. Melakukan kegiatan implementasi

- Pemilihan tempat dan instalasi perangkat keras dan perangkat lunak

- Pemrograman dan pengetesan program

- Pengetesan sistem

c. Tindak lanjut implementasi

Analis sistem masih perlu melakukan tindak lanjut berikutnya setelah sistem baru diimplementasikan. Analis sistem masih perlu melakukan pengetesan penerimaan sistem. Pengetesan ini berbeda dengan pengetesan sistem yang telah dilakukan sebelumnya. Jika pada pengetesan sebelumnya digunakan data test/semu, namun pada pengetesan ini dilakukan dengan menggunakan data sesungguhnya dalam jangka waktu tertentu yang dilakukan oleh analis sistem bersama-sama dengan user.

Implementasi aplikasi partisipatif ini dilakukan dengan cara instalasi dan konfigurasi sistem sehingga dapat diakses sesuai dengan fungsinya. Untuk itu dilakukan pengaturan (setting) tertentu agar aplikasi dapat berjalan sebagaimana mestinya.

\subsection{Hasil Aplikasi Interface Perangkat Mobile}

Agar dapat diakses oleh masyarakat melalui perangkat mobile, maka dilakukan pembangunan dashboard dan interface perangkat mobile yang kompatibel dengan sistem aplikasi webGIS yang telah dikembangkan. Interface mobile bukanlah aplikasi mobile, melainkan interface yang memungkinkan aplikasi webGIS dapat diakses dari perangkat mobile dengan menggunakan web browser yang telah ditentukan. Tampilan interface mobile menu dan interface mobile peta dapat dilihat pada Gambar 14. 


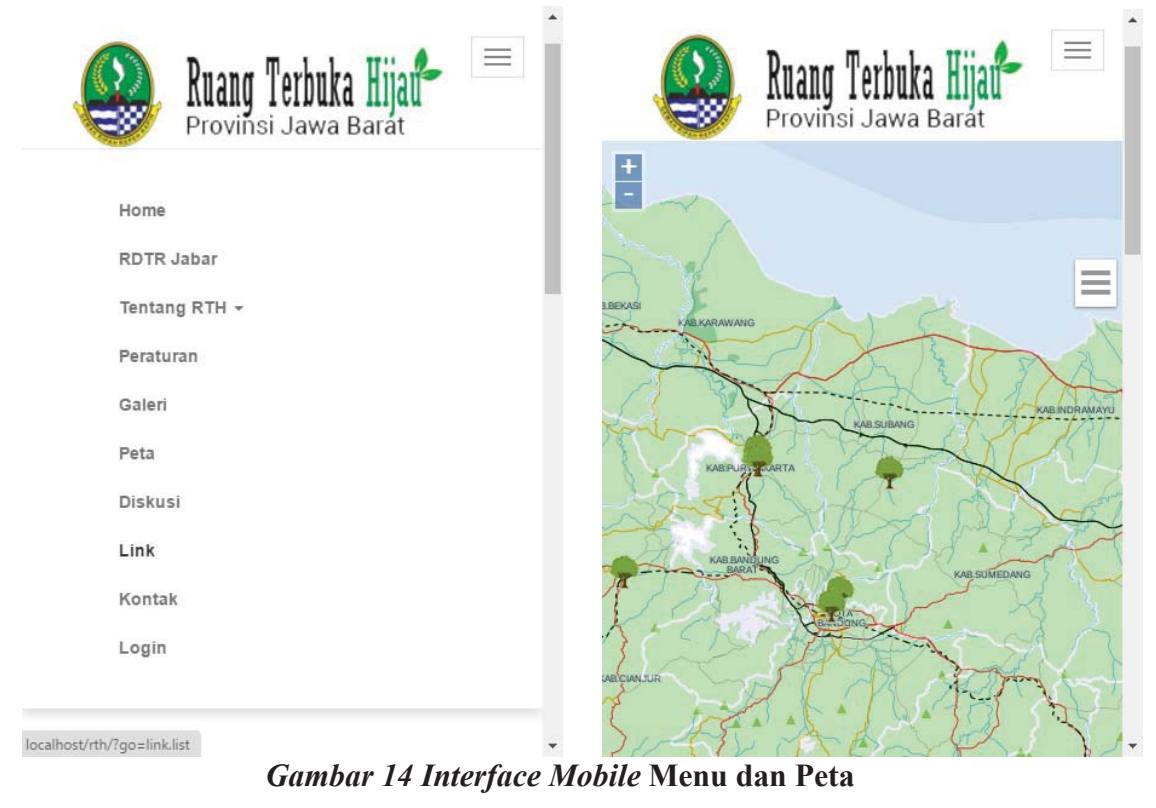

\section{SIMPULAN}

Pengembangan aplikasi partisipatif RTH kabupaten/kota di Provinsi Jawa Barat ini merupakan kegiatan pengintegrasian data RTH dan RDTR kabupaten/kota yang ada (data hasil inventarisasi yang tersedia di Dinas Permukiman dan Perumahan Jawa Barat) yang selanjutnya dikembangkan ke dalam sistem aplikasi yang disajikan ke dalam aplikasi partisipatif berbasis webGIS sehingga dapat diakses oleh publik secara online. Diharapkan hasil penelitian ini dapat memfasilitasi akselerasi pemenuhan target penyelenggaraan RTH di kabupaten/kota dengan membantu kabupaten/kota dalam merencanakan dan mengembangkan pemenuhan target RTH tersebut.

\section{UCAPAN TERIMA KASIH}

Ucapan terima kasih kepada Dinas Permukiman dan Perumahan Provinsi Jawa Barat atas kesediaannya memberikan data yang diperlukan dan PT. EFORT Digital Multisolution atas kerjasamanya dalam penelitian ini.

\section{DAFTAR PUSTAKA}

[1] Peraturan Menteri Pekerjaan Umum No.5/PRT/M/2008 tentang Pedoman Penyediaan dan Pemanfaatan Ruang Terbuka Hijau di Kawasan Perkotaan.

[2] Undang-Undang Republik Indonesia Nomor 26 Tahun 2007 tentang Penataan Ruang.

[3] Peraturan Menteri Pekerjaan Umum No. 01/PRT/M/2014 tentang Standar Pelayanan Minimal Bidang Pekerjaan Umum dan Penataan Ruang.

[4] Astriani, Nadia. (2014). Implikasi Kebijakan Ruang Terbuka Hijau dalam Penataan Ruang di Jawa Barat. Fiat Justisia Jurnal Ilmu Hukum Vol.8 No. 2, April-Juni 2014. Dipetik 1 Maret 2018 dari https://media.neliti.com/media/publications/36952-ID-implikasi-kebijakan-ruang-terbuka-hijaudalam-penataan-ruang-di-jawa-barat.pdf.

[5] Fusebox. (2018). What is Fusebox. Dipetik 5 Januari 2018 dari http://www.fusebox.org/index.cfm/ getting-started/what-is-fusebox/.

[6] Fusebox. (2018). Fusebox Lifecycle Process (FLiP). Dipetik 5 Januari 2018 dari http://corfield.org $/$ FLiP/index.cfm?\&fuseaction=methodology.steps. 